\title{
Recruitment and in situ Renewal Regulate Rapid Accumulation of CD11c+ Cells in the Lung following Intranasal Superantigen Challenge
}

\author{
Guruprasaadh Muralimohan Robert J. Rossi Anthony T. Vella \\ Department of Immunology, University of Connecticut Health Center, Farmington, Conn., USA
}

\section{Key Words}

Superantigen $\cdot$ Lung dendritic cells $\cdot$ Migration

\begin{abstract}
Background: Staphylococcus aureus, a primary source of bacterial superantigen, is known to colonize the human respiratory tract and has been implicated in airway inflammation. The potential pathological effect of staphylococcal enterotoxins on the respiratory tract necessitates a detailed understanding of how they regulate innate immune cells, particularly CD11c-expressing dendritic cells (DCs). Methods: $\mathrm{C} 57 \mathrm{BL} / 6$ mice were challenged intranasally with staphylococcal enterotoxin A (SEA) and at indicated time points lung tissue was perfused, digested and analyzed for CD11c+ expressing cells. Results: The pulmonary CD11c+ cells can be divided into two major populations based on their MHC II expression. One day following intranasal SEA challenge, there was rapid accumulation of CD11c+ cells expressing medium to high levels of MHC II. The peak accumulation of CD11c+ MHC II- population was observed 2 days after SEA challenge; however, careful examination of this cell population revealed that they were heterogeneous, being comprised of cells bearing CD3, CD19, NK1.1 and F4/80 along with varying levels of CD11c. Nevertheless, there was a 2-fold increase of CD11c+ MHC II- (CD3- CD19- NK1.1- F4/80-) cells in the lungs. Conclusion: The mechanism of increase in the $\mathrm{CD} 11 \mathrm{c}+\mathrm{MHC}$ II- immune progenitor population was mainly due to cellular division rather than migration from blood to
\end{abstract}

\begin{tabular}{ll}
\hline KARGER & ( 2008 S. Karger AG, Basel \\
Fax +41613061234 & \\
$\begin{array}{l}\text { E-Mail karger@karger.ch } \\
\text { www.karger.com }\end{array}$ & $\begin{array}{l}\text { Accessible online at: } \\
\text { www.karger.com/iaa }\end{array}$
\end{tabular}

lung. In contrast, the early and rapid accumulation of CD11c+ MHC II ${ }^{\text {hi }}$ cells, conventionally known as DCs, in the lung on day 1 was mostly due to migration from blood. Thus this study examines the pulmonary innate immune response to a powerful immune stimulus. Copyright $\odot 2008$ S. Karger AG, Basel

\section{Introduction}

Superantigens (SAgs) are microbial toxins capable of initiating a massive immune response by stimulating $\mathrm{T}$ cells to release proinflammatory cytokines. They can be of both bacterial and viral origin, but the most common source of SAg is produced by Staphylococcus aureus $[1,2]$. SAgs typically initiate a massive $\mathrm{T}$ cell response by bypassing the conventional antigen processing and presentation pathway and directly cross-linking specific V $\beta$ regions of the T cell receptor with the MHC II molecule on the APC. Thereby they are able to activate large numbers of CD4 and CD8 T cells bearing the preferred V $\beta$ chain $[3,4]$. Based on this mechanism, SAgs cause a number of disorders in humans that include food poisoning, toxic shock syndrome and exacerbation of autoimmune disease [5].

S. aureus is a Gram-positive bacterium that colonizes the skin and mucosa of human beings and several animal species [6]. Twenty-five percent of humans are permanent carriers of $S$. aureus, and under appropriate conditions,

Correspondence to: Dr. Anthony T. Vella Department of Immunology

University of Connecticut Health Center

263 Farmington Ave., MC1319, Farmington, CT 06030 (USA)

Tel. +1 860679 4364, Fax +1 860679 1868, E-Mail vella@uchc.edu 
when the host is most susceptible, S. aureus is capable of causing a variety of disorders like sinusitis, endocarditis, pneumonia, septic arthritis, food poisoning, diarrhea and toxic shock syndrome. Although multiple body sites can harbor S. aureus, it has recently been reported that the anterior nares of the nose is the most frequent carrier site $[7,8]$. Given the predisposition of $S$. aureus to colonize the human respiratory tract, it would not be surprising to find a link between staphylococcal enterotoxins and airway inflammation.

It has been suggested that staphylococcal enterotoxins in the respiratory tract can act as both SAg (by oligoclonal $\mathrm{T}$ cell stimulation) and as conventional allergen. In particular, SAg has been identified as an allergen in certain patients by the detection of IgE antibody specific to staphylococcal enterotoxin B (SEB) [9, 10]. Collectively, these data suggest that there is a potential link between pulmonary disease and $S$. aureus or its entertoxins $[6,11]$. Nevertheless, there are limited studies investigating the effect of staphylococcal enterotoxin exposure to lung. Few studies, with SEB, have shown that when airway mucosa is exposed to SEB, there is recruitment of lymphocytes, especially SEB-specific T cells, eosinophils and neutrophils to the lung. Also studies with HLA-DR3 human MHC II transgenic mice reveal similar results signifying that SEB can cause airway inflammation with features that might closely resemble conditions seen in asthma [12-14].

Given the potential threat SAgs pose to the respiratory tract, it is important to know how they modulate the innate immune system in the lung. Of particular interest is the role of dendritic cells (DCs). Recent evidence suggests that lung DCs play a crucial role in determining initiation of immunity versus tolerance in the lung [15]. There are a number of DC subsets distributed in different compartments of the lung [16] and are classified as conducting airway DC, interstitial DC and alveolar DC. These DCs can also be further characterized as subsets based on the expression of cell surface markers like CD11b, CD8 $\alpha$, CD4, CD103, NK1.1, Gr-1 and mPDCA-1. Each subset appears to fulfill one particular function in the lung with myeloid DCs initiating an immune response, plasmacytoid DCs maintaining tolerance to harmless antigen and CD103 expressing DCs capable of efficient endocytosis $[15,17,18]$. While there are other APCs in the lung like B cells and alveolar macrophages, depletion of CD11c+ DCs, and not other APCs, abrogates the characteristic features of asthma $[19,20]$. Thus, CD11c+ cells appear to play an important role in initiating and sustaining an immune response in the lung.
It is well known that staphylococcal enterotoxins have a profound effect on the adaptive immune system. However, staphylococcal enterotoxins can also influence the cells of the innate immune system, particularly DCs and macrophages. There have been reports that show that staphylococcal enterotoxin A (SEA) can activate DCs, as observed by the upregulation of costimulatory molecules, in a T cell-dependent manner [21]. Our group has shown that SEA conditions the innate immune cells to hyperrespond to various pathogen-associated molecular patterns and can even induce activation and migration of plasmacytoid DCs in a T cell- and IFN- $\boldsymbol{\gamma}$-dependent manner $[22,23]$. SEA was chosen over SEB since SEA has the ability to bind both MHC II $\alpha$ and MHC II $\beta$ chains resulting in the upregulation of costimulatory molecules on the APC along with the production of proinflammatory cytokines. This results in more robust $\mathrm{T}$ cell stimulation compared to SEB, which better mimics the human situation $[24,25]$.

In this study, we examined the effect of intranasal (i.n.) SEA treatment on the lung CD11c+ population. We report that SEA induces the accumulation of CD11c+ MHC II+ and CD11c+ MHC II- cells in the lung. This occurs in two waves, with the first wave resulting in increased numbers of CD11c+ MHC II+ DCs and the second wave resulting in increased numbers of CD11c+ MHC II- cells. We investigated the reason behind this phenomenon, and found that rapid DC accumulation on day 1 was mostly because of recruitment from blood. However, the accumulation of CD11c+ MHC II- cells appears to be an in situ event, with these cells endowed with self-renewal capacity. We hypothesize that the lung responds to a powerful local immune stimulus by inducing CD11c+ MHC II- progenitors for self-renewal.

\section{Materials and Methods}

Mice, Reagents and in vivo Treatments

C57BL/6 mice were purchased from Charles River - National Cancer Institute (Frederick, Md., USA). The green fluorescent protein (GFP)-transgenic mice [C57BL/6-TgN(ACTbEGFP)1Osb] with enhanced GFP expression under the control of a chicken $\beta$ actin promoter have been described previously [26], and were purchased from The Jackson Laboratory (Bar Harbor, Me., USA). TCR $\beta \delta$ KO mice were a kind gift from Dr. T.V. Rajan (Department of Immunology, University of Connecticut Health Center). All mice were maintained in the Central Animal Facility at the University of Connecticut Health Center in accordance with federal guidelines.

SEA was purchased from Toxin Technology (Sarasota, Fla., USA). Mice received $0.2,1$ or $5 \mu \mathrm{g}$ of SEA diluted in balanced salt
60

Int Arch Allergy Immunol 2008;147:59-73
Muralimohan/Rossi/Vella 
solution (BSS) either through the intraperitoneal (i.p.) or through the i.n. route. i.n. challenge involved anesthetizing mice with isoflurane (Vedco, St. Joseph, Mo., USA) in a vaporizing chamber (Vaporizer Sales and Service, Rockmart, Ga., USA). After anesthetization, the indicated dose of SEA, diluted in $50 \mu$ l of BSS, was pipetted on the nostrils of mice, and this volume was inhaled instantly.

PE-conjugated anti-MHC II (M5/114.15.2), anti-CD3 $\varepsilon$ (1452C11), anti-CD19 (MB19-1), anti-CD8 $\alpha$ (53-6.7), anti-F4/80 (BM8), anti-CD11b (M1/70) and control ratIgG2bк, FITC-conjugated anti-MHC II (M5/114.15.2), biotin-labeled anti-MHC II (M5/114.15.2), anti-F4/80 (BM8), control rat IgG2 $\alpha$ and control hamster IgG and were purchased from eBioscience (San Diego, Calif., USA). PE-conjugated anti-NK1.1 (NKR-P1B and NKRP1C) (PK136) and anti-CD4 (GK1.5), FITC-conjugated streptavidin, APC-conjugated anti-CD11c (HL3) and hamster IgG1 1 , PerCP-conjugated streptavidin and CD11b (M1/70), biotin-labeled anti-CD40 (3/23), anti-CD86 (GL1), anti-CD80 (16-10A1), anti-CD3 $\varepsilon$ (145-2C11), anti-CD19 (MB19-1), anti-NK1.1 (NKR$\mathrm{P} 1 \mathrm{~B}$ and NKR-P1C) (PK136) were purchased from BD Biosciences (Mountain View, Calif., USA).

\section{Tissue Processing and Cell Isolation}

Lung tissue was perfused, dissected, and digested in the presence of $1.3 \mathrm{~mm}$ EDTA. After $30 \mathrm{~min}$ of EDTA treatment, the tissue was incubated in collagenase (Invitrogen Life Technologies) for $1 \mathrm{~h}$. Cells were then crushed through nylon mesh cell strainers (Falcon/BD Biosciences) and washed with BSS.

Spleens, peripheral lymph nodes (PLNs; inguinal, axillary and brachial), mesenteric lymph nodes (MLNs) and mediastinal lymph nodes (LN) were homogenized individually in $1 \mathrm{ml}$ of collagenase D (Roche, Indianapolis, Ind., USA) solution $(3.3 \mathrm{mg} / \mathrm{ml}$ collagenase D, $10 \mathrm{mM}$ HEPES, and 2\% FBS in MEM). After a 30 min culture at $37^{\circ} \mathrm{C}$ and $5 \% \mathrm{CO}_{2}, 100 \mu \mathrm{l}$ of $0.1 \mathrm{M}$ EDTA in PBS was added to the well before crushing the cells through nylon mesh cell strainers. These were then treated with ammonium chloride to lyse red blood cells. Blood from B6-GFP mice was directly placed into heparin-containing BSS medium. The red blood cells were lysed using ammonium chloride and washed with BSS. Cells from blood and other tissues were washed with BSS and counted using a Z1 particle counter (Beckman Coulter, Miami, Fla., USA).

\section{Cell Staining and Flow Cytometry}

For flow cytometry, cells were stained with primary Abs in the presence of a blocking solution containing $5 \%$ normal mouse serum (Sigma-Aldrich), $10 \mu \mathrm{g} / \mathrm{ml}$ human $\gamma$-globulin (Sigma-Aldrich), and $0.1 \%$ sodium azide in culture supernatant from the 2.4.G.2 hybridoma (anti-FcR) [27]. After $30 \mathrm{~min}$ on ice, the cells were washed in wash buffer containing $3 \% \mathrm{FBS}$ and $0.1 \%$ sodium azide in BSS. If secondary incubation was necessary, cells were washed and resuspended in wash buffer, and incubated on ice with streptavidin-FITC, streptavidin-PE or streptavidin-PerCP for $30 \mathrm{~min}$. In some experiments a number of primary antibodies, conjugated either to Biotin or PE, were used to exclude major cell types (dump gating). For figure $1 \mathrm{a}$ and $\mathrm{b}$, we gated on all the CD11c+ MHC II+ cells. This was done to include all DC subsets that might be expressing intermediate levels of CD11c or MHC II. Subsequently, we gated on CD11 $\mathrm{c}^{\text {hi }}$ MHC II+ cells to analyze the bona fide DC population. The cells were assayed on a FACSCali- bur (BD Biosciences, Mountain View, Calif., USA) flow cytometer and data were analyzed using either CELL Quest software (BD Biosciences) or FlowJo software (Tree Star, Ashland, Oreg., USA).

\section{Adoptive Transfer of GFP+Blood Cells}

As described above, peripheral blood cells were collected from the B6-GFP-transgenic mice and from 0.8 to $2 \times 10^{7}$ were adoptively transferred into $\mathrm{C} 57 \mathrm{BL} / 6$ mice. Adoptive transfer refers to intravenous injection. One day after transfer, the mice were challenged i.n. with BSS or SEA $(1 \mu \mathrm{g})$. For some experiments mice were also challenged i.p. with nothing or SEA $(1 \mu \mathrm{g})$. At indicated time points after challenge, mice were sacrificed and various tissues like lung, spleen, PLN, MLN and mediastinal LNs were processed as described above.

\section{Isolation of CD11c+ MHCII-Cells from the Lung Tissue}

Single cell suspensions from lung tissue were incubated with MHC II microbeads (Miltenyi Biotec, Auburn, Calif., USA). The MHC II+ cells were depleted by passing them over a magnetic bead depletion column. The flow-through was approximately $95 \%$ MHC II-. These MHC II-depleted cells were then incubated with $\mathrm{CD} 11 \mathrm{c}+$ microbeads and positively selected for CD11c+ cells.

\section{Propidium Iodide Staining for Cell Cycle Analysis}

For intracellular propidium iodide staining, purified CD11c+ cells obtained from MHC II-depleted fractions were stained with anti-CD11c APC and a cocktail of anti-CD3 3 , anti-CD19, antiNK1.1 and anti-F4/80 FITC on ice for $30 \mathrm{~min}$. After several washes, the cells were fixed and pelleted. The pelleted cells were then resuspended in solution containing $5 \mathrm{mM}$ EDTA, $5 \mathrm{mg} / \mathrm{ml}$ propidium iodide, $5 \mathrm{mg} / \mathrm{ml} \mathrm{RNaseA}$, and $0.3 \%$ saponin in PBS. The presence of saponin permeabilizes the cell membrane allowing propidium iodide to bind to the DNA of viable cells. All stained cells were assayed on a FACSCaliber by collecting the cell events at a minimum of $10^{4} / \mathrm{s}$. The data were analyzed using FlowJo software (Tree Star).

\section{Results}

\section{i.n. SEA Treatment-Induced Accumulation and Activation of CD11c+ MHCII+Cells $24 \mathrm{~h}$ after Challenge}

To identify if i.n. SEA treatment had any effect on the lung CD11c+ population, we challenged mice with BSS or $1 \mu \mathrm{g}$ of SEA. The dose of SEA was determined after careful titration analysis (data not shown). To characterize the lung CD11c+ cells, forward scatter and side scatterlo cells were gated and analyzed for the expression of CD11c+ MHC II+ and CD11c+ MHC II- cells. CD11c expression was determined by isotype control staining (fig. 1a). MHC II expression was also determined by isotype control staining (data not shown) and the gates were drawn to include both MHC II ${ }^{\text {hi }}$ and MHC II ${ }^{\text {lo }}$ expression. The side scatter ${ }^{\text {hi }}$ cells were not included in the 
Fig. 1. Lung CD11c+ MHC II+ DCs increase in number and are activated 1 day after i.n. SEA challenge. a To characterize the effect of SEA on lung CD11c+ cells, the $\mathrm{CD} 11 \mathrm{c}+\mathrm{MHC} \mathrm{II}+$ and CD11c+ MHC IIsubpopulations were analyzed. An example of gating and analysis strategy is shown. b To study the effect of i.n. SEA challenge, lung tissue was isolated at indicated time points from mice challenged with BSS or $1 \mu \mathrm{g}$ SEA and the percentage and total number of CD11c+ MHC II+ DCs were calculated. Data are from a minimum of 3 independent experiments $(n=6-8$ in the BSS and $n=6-8$ in the SEA group) and presented as mean \pm SEM. $c$ In other experiments, CD11chi MHC II+ cells were analyzed for the surface expression of CD86 and CD40 (or their respective isotype controls) after i.n. SEA challenge $(1 \mu \mathrm{g})$. These are 1 representative experiment of 3 performed. The bar graphs show the mean fluorescence intensity of CD86 and CD40 calculated at 12, 24 and $48 \mathrm{~h}$ time points after BSS (grey bars) or $1 \mu \mathrm{g}$ i.n. SEA challenge (open bars). Values are from 3 independent experiments $(n=6-8$ in the BSS and $n=6-8$ in the SEA group) and presented as mean \pm SEM.
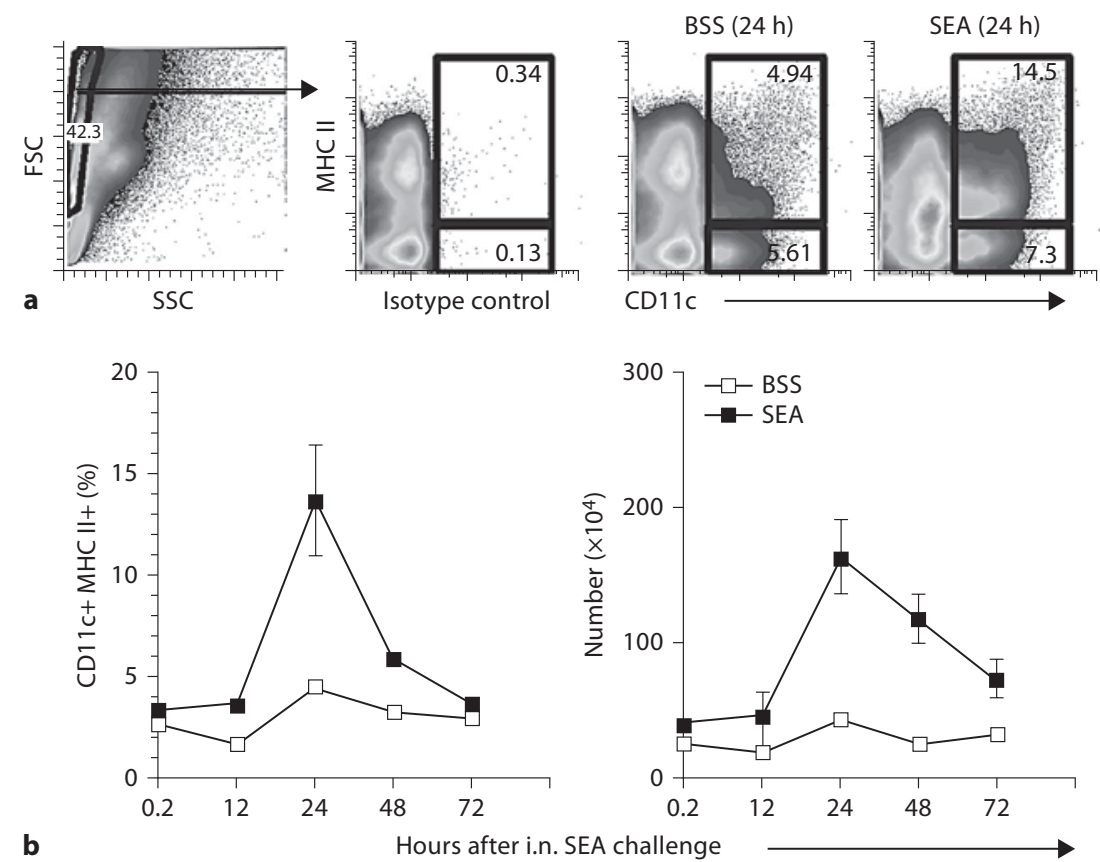

b

Hours after i.n. SEA challenge
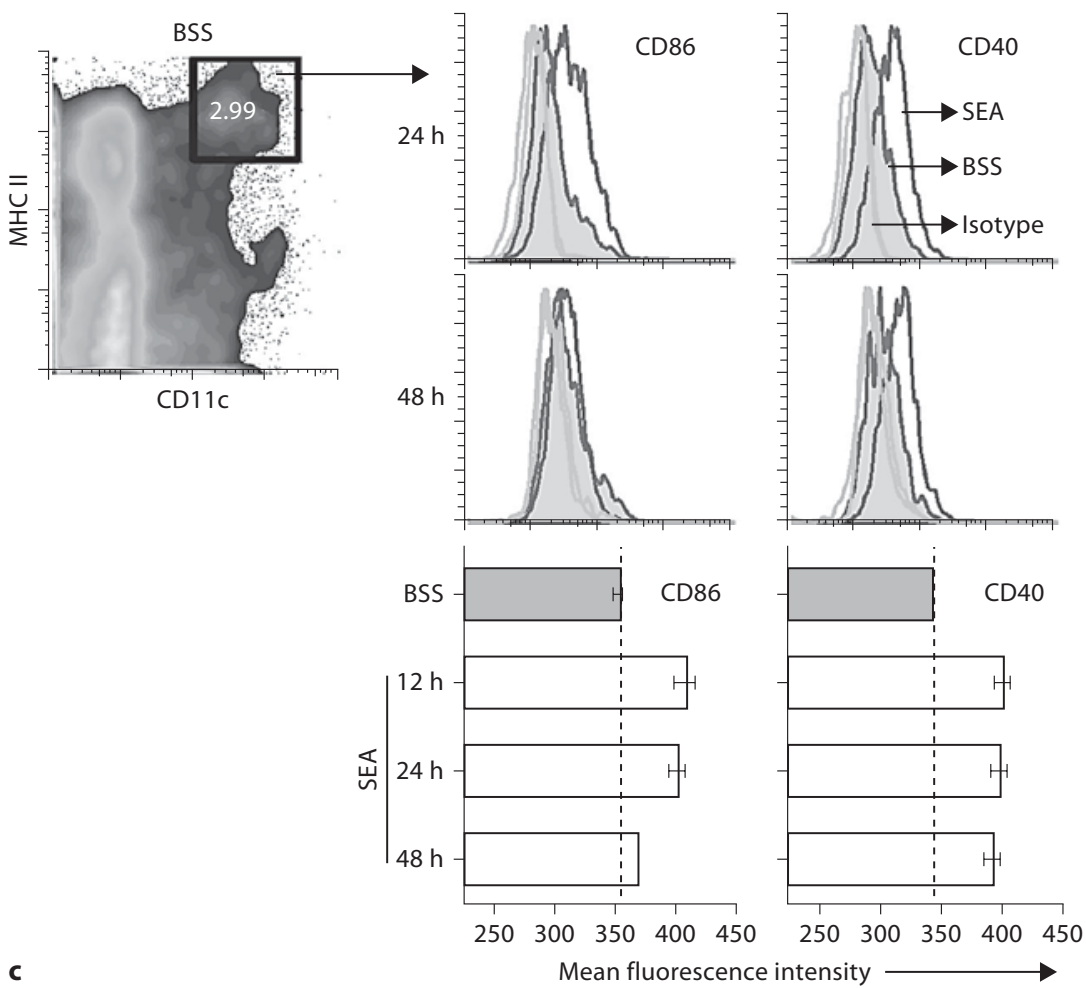

c

Mean fluorescence intensity 
analysis region as they stained positive for both CD11c and Siglec-F. Therefore, the gates for forward and side scatter were drawn to carefully exclude Siglec-F+ macrophages [17] (online suppl. fig. 1, www.karger.com/ doi/10.1159/000128660). An exhaustive time kinetics study was done to monitor the percentage and number of CD11c+ MHC II+ cells in response to BSS or $1 \mu \mathrm{g}$ of SEA. Mice were sacrificed at $0.2,12,24,48$ and $72 \mathrm{~h}$ after challenge. The percentage of CD11c+ MHC II+ cells, $24 \mathrm{~h}$ after challenge, was 3 -fold over BSS treatment. Interestingly, the percentage decreased by $48 \mathrm{~h}$ and the fold increase over BSS treatment was now 1.7-fold. This trend was also observed in numbers, where a 3.7-fold increase of CD11c+ MHC II+ cells was observed $24 \mathrm{~h}$ following challenge (fig. 1b). The CD11c+ MHC II+ cells have traditionally been described as DCs [28], and results from figure $1 \mathrm{~b}$ suggest that the peak of DC accumulation in the lung is on day 1 . To determine if these cells were bona fide DCs, it was important to analyze their activation status. Analyzing activation markers on CD11c $\mathrm{c}^{\text {hi }} \mathrm{MHC}$ II+ cells enables easier tracking of changes in their expression levels. Therefore, CD11 chi MHC II+ cells (fig. 1c, top left) were examined for the expression of various activation markers like CD80, CD86, CD40, 4-1BBL and OX40L. The lung DCs did not upregulate $4-1 \mathrm{BBL}$ or OX40L in response to $1 \mu \mathrm{g}$ of SEA (data not shown); however, these cells did upregulate expression of CD86 and CD40 (fig. 1c, top panel), along with a moderate increase of CD80 (data not shown). The expression levels of CD86 peaked by $12 \mathrm{~h}$ after which it started to gradually decline and was almost at base level by $48 \mathrm{~h}$. Interestingly, CD 40 expression peaked by $12 \mathrm{~h}$ and continued to remain high even $48 \mathrm{~h}$ postchallenge (fig. $1 \mathrm{c}$, bottom panel). Thus the CD11c+ MHC II+ cells were bona fide DCs that were activated and increased in numbers in response to SEA challenge.

\section{i.n. SEA Treatment Induced Peak Accumulation of} CD11c+ MHC II-Cells 48 h after Challenge

Apart from the CD11c+ MHC II+ DCs, SEA also had an effect on the CD11c+ MHC II- population. At $24 \mathrm{~h}$ post-SEA challenge, the percentage of CD11c+ MHC IIcells was only 1.6 -fold over BSS treatment while there was a 3-fold increase in percent of DCs at the same time point (compare fig. $1 \mathrm{~b}$ to fig. $2 \mathrm{a}$ ). However at $48 \mathrm{~h}$, when the fold increase in percent of DCs was 1.7, the CD11c+ MHCIIcells increased in percentage by 3.3 -fold over BSS treatment. This pattern was observed in the total numbers as well (fig. 2a). To uncover whether these cells expressed any DC-like characteristics, expression levels of costimu- latory molecules like CD86 and CD40 were analyzed. Compared to BSS treatment, the expression of both the costimulatory molecules appeared to be upregulated by $12 \mathrm{~h}$. While the expression levels of CD40 reduced by $48 \mathrm{~h}, \mathrm{CD} 86$ expression remained unchanged after activation (fig. 2b). However, when compared to DCs, the MFI of costimulatory molecule expression in CD11c+ MHC II- population was at least 80-100 units lower (compare fig. 1c, bottom panel to fig. $2 \mathrm{~b}$ ) suggesting that the expression levels were slightly over background staining. Thus, SEA induced accumulation of lung CD11c+ cells with a first wave resulting in an increase in the percentage and number of CD11c+ MHC II+ DCs at $24 \mathrm{~h}$, followed by a second wave resulting in an increase in the CD11c+ MHC II- cell population at $48 \mathrm{~h}$. This CD11c+ MHC II- cell population could potentially be a progenitor for different immune cell types, and cells with a similar phenotype have been described by other groups as a putative immediate DC precursor population [29-32].

CD11c+ MHC II- Lineage- $(C D 3+C D 19+$ NK1.1+ F4/80+) Cells Increased in Percentage $48 \mathrm{~h}$ after SEA Challenge

The CD11c+ MHC II- population is highly heterogeneous and is comprised of T cells, B cells, NK cells and macrophages, all of which express varying levels of CD11c on their surface after activation. Thus, it becomes very important to examine the effect of SEA on CD11c+ MHC II-CD3- CD19- NK1.1- F4/80- population. Since CD3, CD19, NK1.1 and F4/80 are markers for T cells, B cells, NK cells and macrophages, we designated the cocktail of CD3+ CD19+ NK1.1+ F4/80+ cells as 'lineage+' cells. In figure 2, we observed a 3.3-fold increase in the percentage of SEA-treated CD11c+ MHC II- cells over the vehicle BSS treatment. Fold difference in percentage analyzed here as increase in percentage also resulted in an increase in actual numbers at this time point. To examine if there still existed a fold increase in the percentage of SEA-treated CD11c+ MHC II- cells after eliminating lineage+ cells, a dump gate analysis was performed, where PE-conjugated anti-CD3, anti-CD19, anti-NK1.1 and anti-F4/80 were excluded and the lineage- cells were analyzed for the expression of CD11c and MHC II. A 3.3-fold increase in the percentage of CD11c+ MHC II- cells was observed without excluding the lineage+ cells (fig. 3a), while a 2.8fold increase was observed after excluding the lineage+ contaminants (fig. 3b) demonstrating that excluding the lineage + cells had a minor effect. To determine which cell type was the cause for contamination, we first included CD19 while excluding all other lineage+ cells in our anal- 


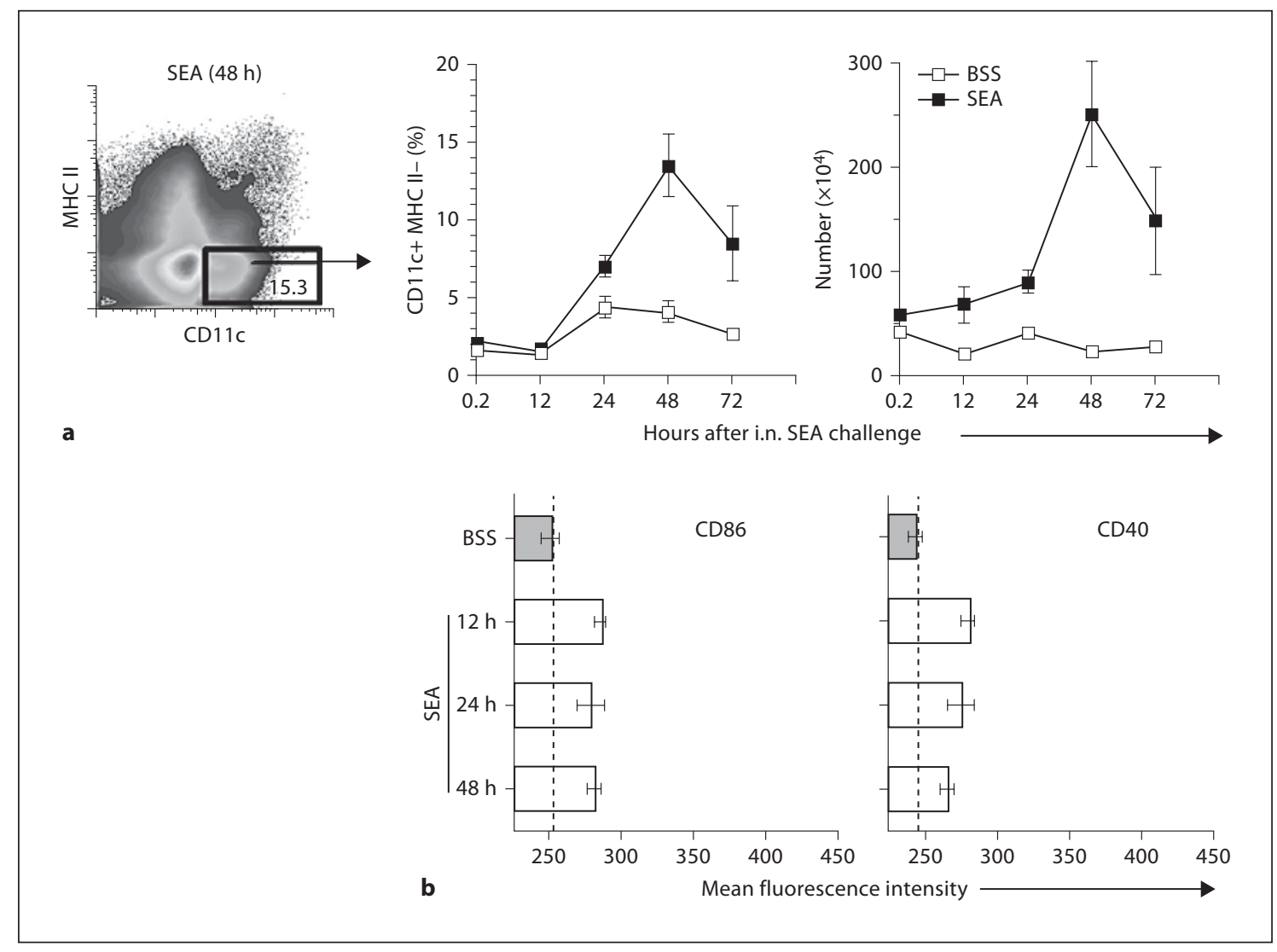

Fig. 2. Lung CD11c+ MHC II- subpopulation increases in number 2 days after i.n. SEA challenge. a An example of gating and analysis strategy for surface expression of CD11c and MHC II is shown (left panel). The percentage and total number of CD11c+ MHC II- cells were calculated at indicated time points (right panels). These data were derived from those in figure $1 \mathrm{~b} ; 3$ experiments ( $n=6-8$ in the BSS and $n=6-8$ in the SEA group) represented as

ysis region. Including $\mathrm{CD} 19$ reduced the percent of total CD11c+ MHC II- cells in the BSS and SEA treatments; however, the fold increase of SEA over BSS was now 3.6 (fig. 3c). Inclusion of anti-F4/80, while excluding all other lineage + cells in the analysis region, altered the percent of CD11c+ MHC II- cells resulting in a fold increase of only 1.7-fold (fig. $3 \mathrm{~d}$ ). Nevertheless the major contaminant of CD11c+ population was NK cells. When antiNK1.1 antibody was included in the analysis region while excluding other lineage + cells, the total percent of CD11c+ MHC II- cells increased significantly in both the BSS and SEA treatments. Though NK1.1 cells constituted a large percent of CD11c+ MHC II- cells, the fold increase in SEA treatment over BSS was only 1.9 (fig. 3e). This supports the notion that SEA treatment did increase the percent of CD11c+ MHC II- progenitor cell population in mean \pm SEM. $\mathbf{b}$ The bar graphs show the mean fluorescence intensity of CD86 and CD40 calculated at 12, 24 and $48 \mathrm{~h}$ time points after BSS (grey bars) or $1 \mu \mathrm{g}$ i.n. SEA challenge (open bars). These are data derived from the same experiments shown in figure $1 \mathrm{c} ; 3$ independent experiments $(\mathrm{n}=6-8$ in the BSS and $\mathrm{n}=$ $6-8$ in the SEA group) presented as mean \pm SEM.

the lung, although it was necessary to carefully to exclude all possible lineage contaminants.

\section{GFP+DCs Trafficked from Blood to LNs after i.p. SEA Challenge}

Given the increase in numbers of lung CD11c+ MHC II+ DCs on day 1 and the increase in the number of CD11c+ MHC II- progenitor cell population on day 2, it was essential to determine the dynamics of this increase. Blood has been shown to be a reservoir of CD11c+ MHC II+ DCs and CD11c+ MHC II- putative precursor population [30-32]. We had demonstrated earlier that, in response to peripheral SEA challenge, the number of conventional (all DCs except plasmacytoid DCs) and plasmacytoid DCs increased in the spleen, PLN and MLN by $24 \mathrm{~h}$ [22], and this increase was not the result of DCs rep- 
Fig. 3. SEA induced an increased percentage of CD11c+ MHC II- lineage- (CD3+ CD19+ NK1.1+ F4/80+) cells. a An example of gating strategy to analyze CD11c+ MHC II- cells is shown (left panel). Data are from 3 independent experiments with an $n=7$ in each bar and represented as mean \pm SEM. $\mathbf{b}$ An example of gating strategy to analyze CD11c+ MHC II- cells after excluding lineage+ (CD3+, CD19+, NK1.1+ and F4/80+) cells is shown (left panel). c An example of gating strategy to analyze CD11c+ MHC II- cells after excluding lineage+ $(\mathrm{CD} 3+, \mathrm{F} 4 / 80+$ and $\mathrm{NK} 1.1+$ but not CD19+) cells is shown (left panel). d An example of gating strategy to analyze CD11c+ MHC II- cells after excluding lineage+ $(\mathrm{CD} 3+, \mathrm{CD} 19+$ and NK1.1+ but not F4/80+) cells is shown. e An example of gating strategy to analyze CD11c+ MHC II- cells after excluding lineage + (CD3+, CD19+ and $\mathrm{F} 4 / 80+$ but not NK1.1+) cells is shown (left panel). The bar graph in the right panel shows the percentage of gated CD11c+ MHC II- cells 2 days after BSS or SEA i.n. challenge. Fold increase in percentage of CD11c+ MHC II- cells after SEA treatment is indicated. Data are from 3 independent experiments with an $n=6$ in each bar and represented as mean \pm SEM.
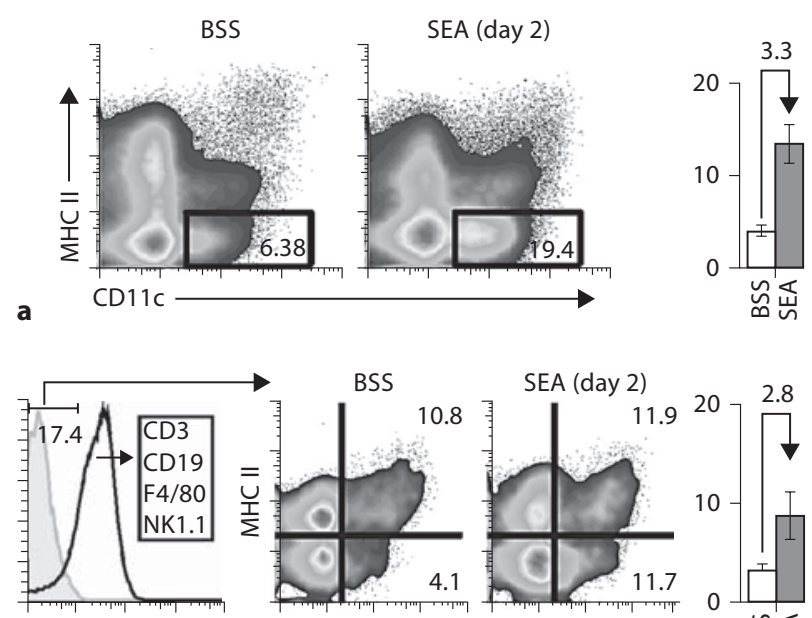

b
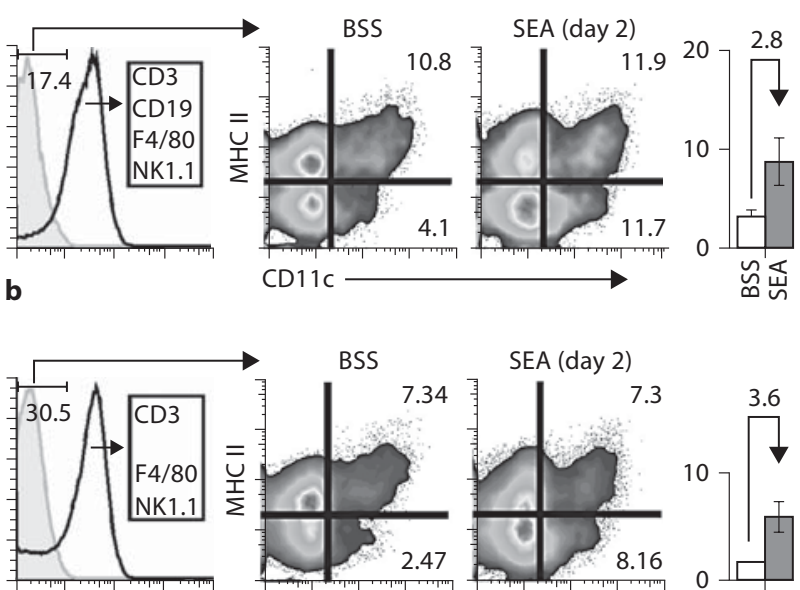

c
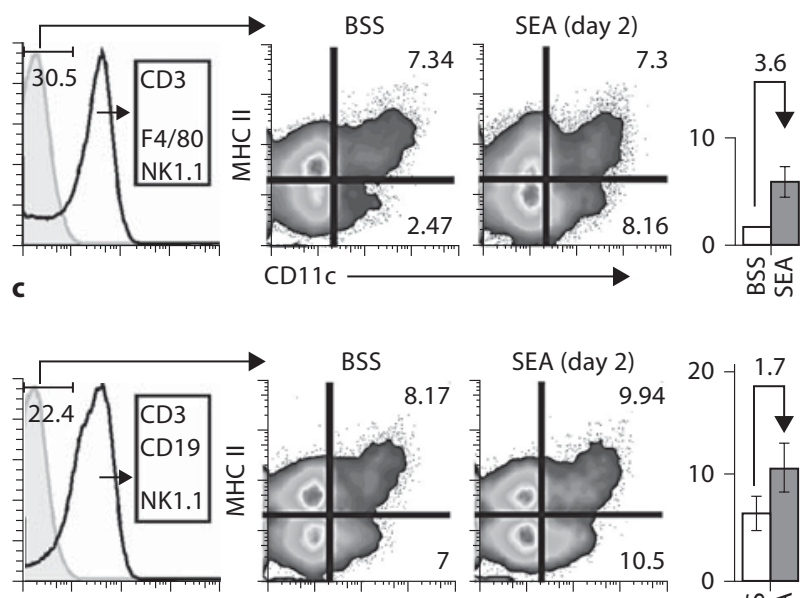

d
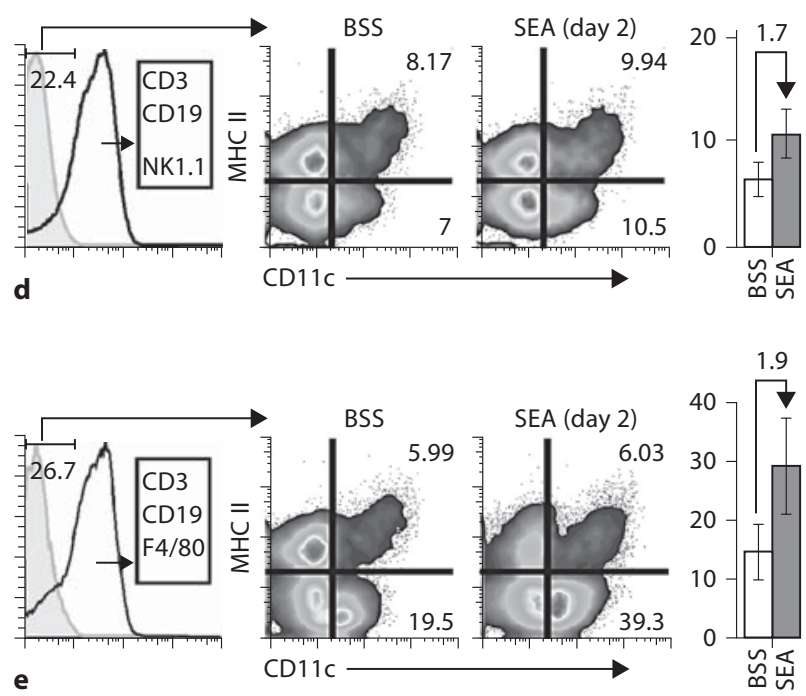

licating in situ (data not shown). Therefore, we deduced that DC accumulation in the tissues and LNs must be the result of migration from blood and to investigate this process a GFP transfer system was set up as shown (fig. 4a). Naive C57BL/6-green fluorescent protein (B6GFP) blood cells consisted of $2.2 \pm 0.2 \%$ CD11c+ MHC
II- cells and $0.16 \pm 0.04 \%$ CD11c+ MHC II+ DCs (data not shown). We tracked GFP+ cells $24 \mathrm{~h}$ after i.p. SEA challenge and observed preferential recruitment of GFP+ CD11chi mPDCA-1- cells to the PLN (fig. 4b). Preferential recruitment of GFP+CD11 $\mathrm{c}^{\text {hi }} \mathrm{mPDCA}-1-$ cells to the MLN was also observed in response to SEA, but very lit- 


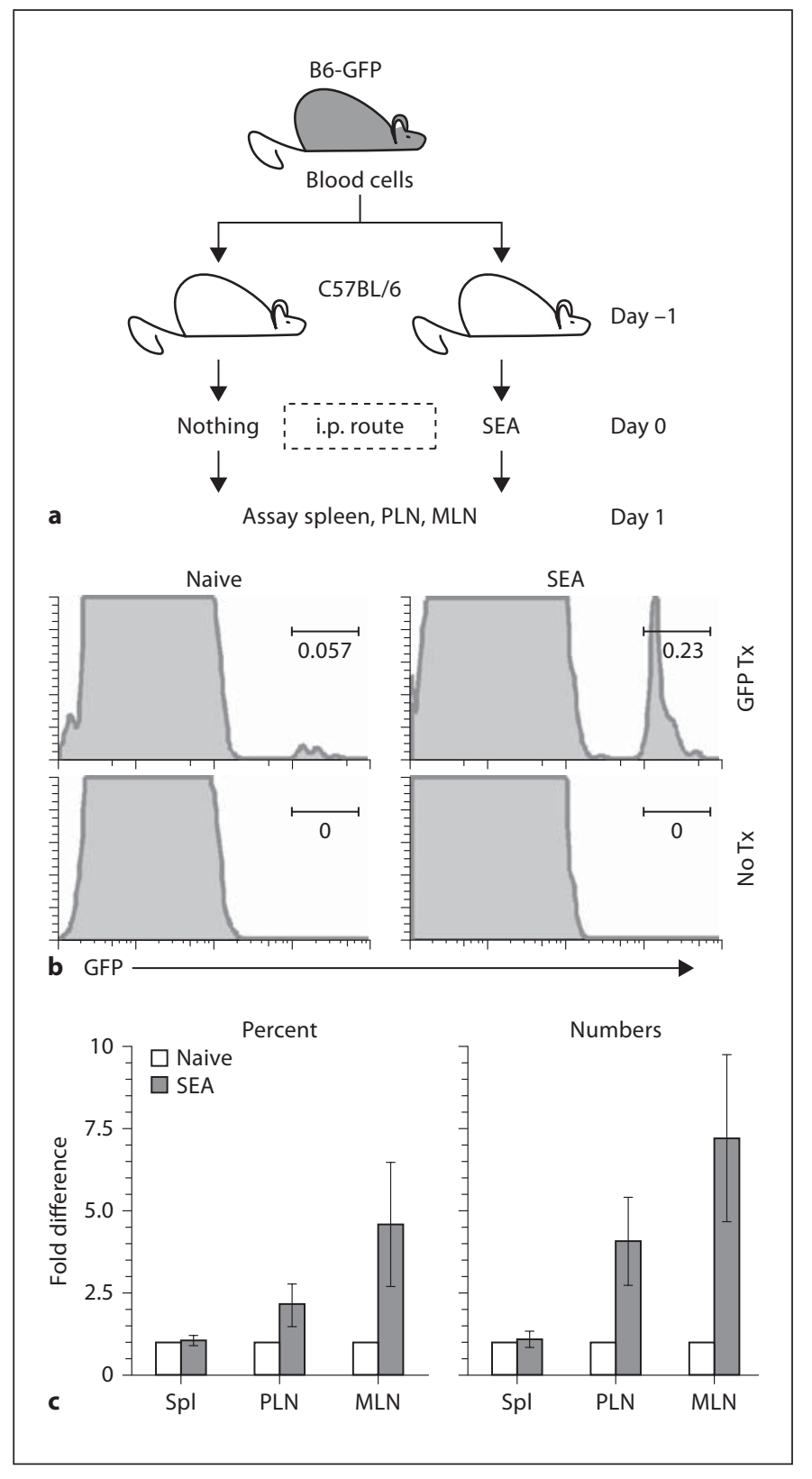

Fig. 4. GFP+ DCs are preferentially recruited to the LNs from blood after i.p. SEA challenge. a Schematic showing GFP transfer experiments. $\mathbf{b}$ Gating strategy to detect GFP+ CD11c+ mPDCA1- cells before and after SEA challenge. GFP+ cells were gated (upper panels) based on no transfer controls (lower panels). Data are from PLN and is 1 representative experiment of 6 performed. c The left bar graph shows the average fold difference in percentage of SEA-treated GFP+ CD11c+ mPDCA-1- cells over naive, which was equated to 1 -fold. The right bar graph shows the average fold difference in total number of SEA-treated GFP+ CD11c+ mPDCA-1- cells over naive. The bar graphs were generated by calculating the fold difference of SEA over naive in each individual mouse and then calculating the mean fold difference and SEM. The SEA data are from 6 independent experiments $(n=6)$ represented as mean \pm SEM. $\mathrm{Spl}=$ Spleens. tle effect was observed in spleen. The average fold increase in percent GFP+CD11 ${ }^{\text {hi }}$ mPDCA-1- cells in the spleen was $1.07 \pm 0.17$; PLN was $2.16 \pm 0.64$ while the MLN was $4.58 \pm 1.88$. The average fold increase in the number of these cells was $1.12 \pm 0.24$ fold over BSS in spleen, $4.08 \pm 1.33$ for PLN and $7.22 \pm 2.56$ for the MLN (fig. 4c). Table 1 shows the actual number of GFP+ CD$11 c^{\text {hi }}$ mPDCA-1- cells recruited from blood to different tissues from all the experiments. This suggested that the robust and preferential increase in DC numbers observed in peripheral and MLNs after an i.p. SEA challenge compared to naive was a result of migration from blood.

\section{Recruitment of GFP +CD11c ${ }^{\text {hi }} M H C$ II + DCs Is}

Observed in the Lung by Day 1 following Intransal

\section{SEA Challenge}

Using this peripheral blood cell tracking system, the mechanism behind accumulation of DCs (CD11 $\mathrm{c}^{\text {hi }} \mathrm{MHC}$ II+ cells) after i.n. SEA challenge was investigated in the pulmonary immune system. As shown in the schematic, GFP blood cells were adoptively transferred, and a day later mice were challenged i.n. with SEA (fig. 5a). On day 1 after challenge, the percentage of total GFP+ cells that entered the lungs or the draining mediastinal LN was almost the same. In fact, the average percentage of bulk GFP+ cells that entered the lungs was exactly $0.20 \%$ for both BSS and SEA treatments (fig. 5b). The actual number of bulk GFP+ cells entering the lungs was also approximately the same, with BSS treatment resulting in an average of 36,856 cells while SEA treatment resulted in the recruitment of an average of 40,790 cells. The mediastinal LN followed a similar trend, although there was a 2 -fold increase in the actual bulk numbers recruited (data not shown). We next investigated if CD11c ${ }^{\text {hi }}$ MHC II+ DCs migrated from blood to the lungs or to the mediastinal LN on day 1 (fig. 5c). The percentage of GFP+ CD$11 \mathrm{c}^{\text {hi }}$ MHC II+ DCs that entered the lungs after BSS treatment was $0.04 \%$, while SEA treatment resulted in an increase to $0.06 \%$. However, no such increase was seen in the mediastinal LN; on the other hand, there was a 1.6fold reduction (fig. 5d). Although the fold increase in the percentage of GFP+CD11c ${ }^{\text {hi }}$ MHC II+ DCs that entered the lung after SEA challenge was 1.4-fold, a 2.9-fold increase was observed in the actual numbers (fig. $5 \mathrm{e}$ ). In the mediastinal LN, the actual number of DCs that migrated was very few and it was difficult to obtain reproducible numbers. The immediate requirement of DCs to the lung following a powerful local immune response might explain the failure of GFP+ DCs to traffic to the draining LNs. This suggests that, 1 day after i.n. SEA challenge, 
Table 1. Intraperitoneal SEA challenge induces migration of transferred GFP+ cells from blood to LNs

\begin{tabular}{|c|c|c|c|c|c|c|c|}
\hline \multirow[t]{3}{*}{ Experiment } & \multirow[t]{3}{*}{ Mouse } & \multicolumn{6}{|c|}{ Total number of GFP+CD11chi mPDCA-1- cells } \\
\hline & & \multicolumn{2}{|l|}{ PLN } & \multicolumn{2}{|l|}{ MLN } & \multicolumn{2}{|l|}{ spleen } \\
\hline & & naive & SEA & naive & SEA & naive & SEA \\
\hline 1 & 1 & 70,200 & 110,250 & 36,210 & 126,000 & 89,600 & 78,720 \\
\hline 2 & 1 & 9,975 & 93,610 & 1,050 & 13,176 & 63,624 & 133,100 \\
\hline 3 & 1 & 23,087 & 58,942 & 1,152 & 19,759 & 225,799 & 343,683 \\
\hline 4 & 1 & 8,448 & 54,720 & 2,686 & 13,780 & 84,400 & 93,280 \\
\hline 5 & 1 & 9,715 & 35,765 & 1,992 & 8,898 & 103,140 & 58,776 \\
\hline 6 & 1 & 264,876 & 219,760 & 68,076 & 39,101 & 162,121 & 93,588 \\
\hline
\end{tabular}

GFP blood cells $\left(0.8-2 \times 10^{7}\right)$ were adoptively transferred to $\mathrm{B} 6$ mice on day -1 . On day 0 , recipient mice were challenged with nothing or $1 \mu \mathrm{g}$ of SEA delivered via the i.p. route. The mice were then sacrificed on day 1 and PLN, MLN and spleen were isolated to track GFP+ CD11c ${ }^{\text {hi }}$ mPDCA-1- cells. Data represent actual number of GFP+CD11 $c^{\text {hi }}$ mPDCA-1- cells detected in various tissues and are from 6 different experiments $n=6$ ).

there is a marginal increase in the total number of cells that enter the lungs and a 2.9 -fold increase in the number

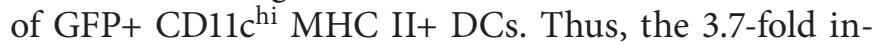
crease in CD11c+ MHC II+ cell numbers observed on day 1 (fig. 1b) was partly due to migration of DCs from the blood to the lung in response to pulmonary SEA challenge.

\section{Migration of Cells to the Lungs Is Restricted by Day 2 following i.n. SEA Challenge}

To investigate the increase of CD11c+ MHC II- CD3 CD19- NK1.1- F4/80 - cells in the lungs on day 2 (fig. 2), we employed the same strategy of adoptively transferring GFP+ blood cells as shown in the schematic (fig. 6a). When the percentage of GFP+ bulk cells that entered the lungs on day 2 after SEA challenge was analyzed, an unexpected 2 -fold reduction was observed with the percentage going down from 0.20 to $0.10 \%$. In contrast, there was a 2 -fold increase in the percentage of GFP+ bulk cells entering the draining mediastinal LN (fig. 6b). These bulk GFP+ cells were predominantly lymphocytes that were responding to SEA stimulus (data not shown). This showed that the lung constricted the migration of cells from blood, whereas the reverse occurred in the mediastinal LN. To analyze the migration pattern of GFP+ CD11c+ MHC II- CD3- CD19- NK1.1- F4/80- cells, the gating strategy shown in figure $6 \mathrm{c}$ was employed. In the 3 experiments performed with a total of 7 mice, very few to no GFP+ CD11c+ MHC II- lineage- cells entered the lung or mediastinal LN after SEA challenge; however, there were a few GFP+ CD11c+ MHC II+ lineage- DCs that entered the lung and mediastinal LN (table 2). Therefore, given the predisposition of the lung to deny immigration of cells on day 2, we hypothesized that increases in CD11c+ MHC II- lineage- progenitor population must be the result of its capacity to self-renew in situ.

\section{Lineage-CD11c+MHC II-Cells Self-Renewed in the Lung after SEA Challenge}

To test this idea, CD11c+ MHC II- cells were isolated from the lungs of BSS or $36 \mathrm{~h}$ i.n. SEA-treated mice and analyzed for DNA content using propidium iodide staining [33]. The gates for the forward and side scatter analysis were drawn so that the CD11c+ population was separated from cellular doublets and the contaminating lineage+ cell population (fig. 7a). Again the gates for the CD11c versus lineage+ cells were set to include only the CD11c+ cells without any contaminants. Any shift in the position of the gates resulted in the inclusion of lineage+ cells, which did proliferate in response to SEA. Therefore without a careful gating strategy, the proliferation of lineage+ cells could be mistaken for CD11c+ lineage- cells. Analysis of the CD11c+ MHC II- lineage-population, after BSS treatment, uncovered a very small percentage of cells in S phase of cell cycle, while there was an identifiable dividing population after SEA challenge (fig. 7b). Specifically, $36 \mathrm{~h}$ after SEA i.n. challenge, $5.6 \pm 0.8 \%$ of the CD11c+ MHC II- lineage- cells were in S phase, which was a 10.4-fold increase over BSS treatment (fig. 7c). To find out if this self-renewal process after SEA challenge was a $\mathrm{T}$ cell-based inflammatory-dependent phenomenon, a similar experiment was performed in B6 
Fig. 5. Partial recruitment of GFP+ MHC II+ CD $11 c^{\text {hi }}$ DCs to the lungs after i.n. SEA challenge. a Schematic showing GFP transfer experiment. b The bar graph shows the percentage of bulk GFP+ cells entering the lung or mediastinal LN (MedLN) from blood 1 day after challenge. c Gating strategy to analyze the expression of GFP+ MHC II+ CD11chi cells. $\mathbf{d}$ The bar graphs show the percentage of GFP+ MHC II+ CD11c ${ }^{\text {hi }}$ cells in the lung and mediastinal LN after BSS or SEA treatment. The fold difference in SEA over BSS treatment for both lung and mediastinal LN is indicated by the arrows. e The bar graph shows the total numbers of GFP+ MHC II+ CD11chi cells in the lung after BSS or SEA treatment. The fold difference in SEA over BSS treatment is indicated by the arrow. All data are from 4-6 independent experiments ( $\mathrm{n}=7-9$ for the BSS and $\mathrm{n}=7-9$ for the SEA group) represented as mean \pm SEM.

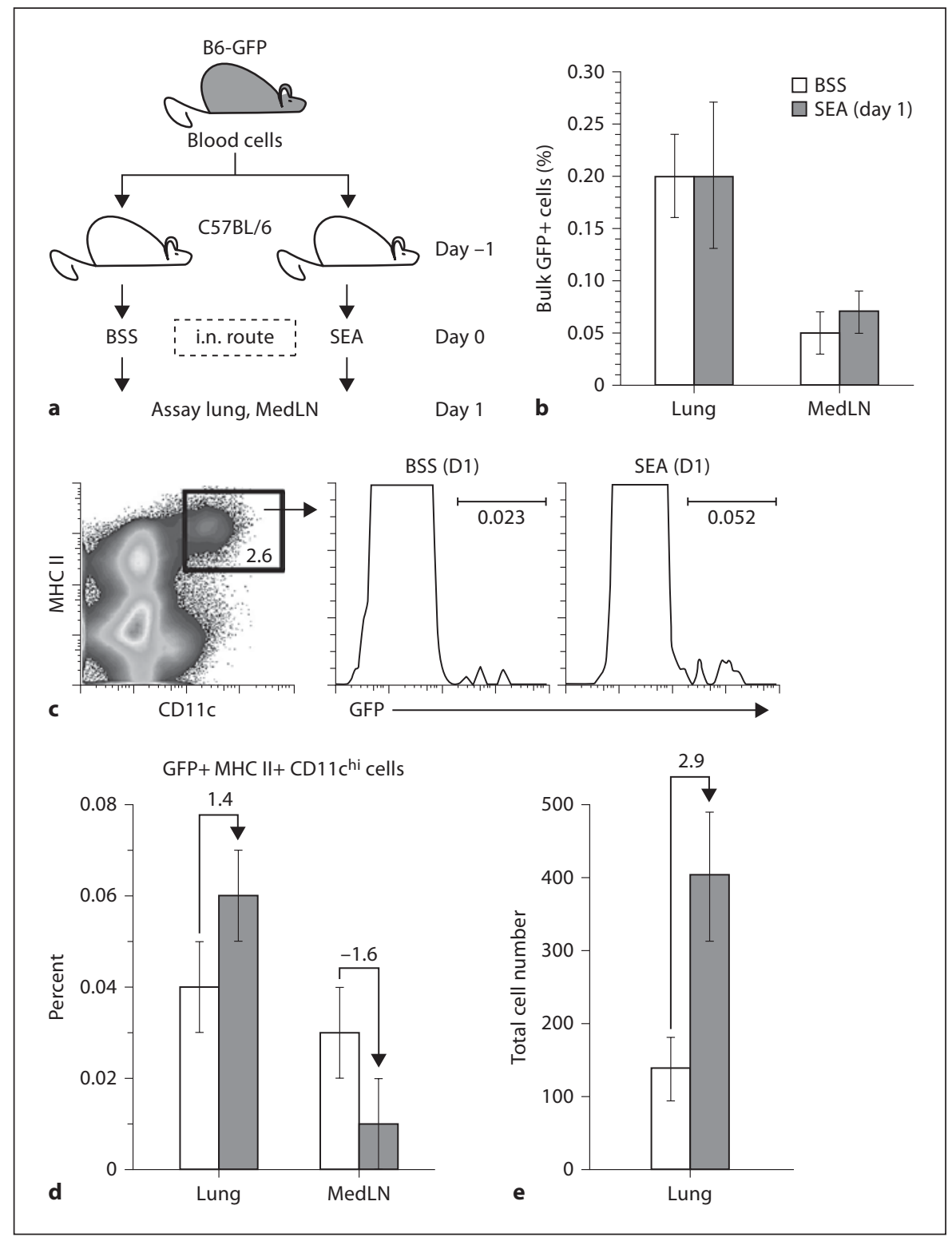

TCR $\beta \delta$ KO mice. Data from 3 different experiments with a total of 6 mice showed that in the absence of T cells, the ability of CD11c+ MHC II- lineage- cells to enter cell cycle was restricted (table 3 ). The average fold increase in percent of cells entering $S$ phase in the B6 TCR $\beta \delta \mathrm{KO}$ mice after SEA challenge was minimal, and in these experiments the wild-type control was 4.5 -fold greater than BSS treatment. Thus, unlike cell migration from blood to lung, which was significantly limited, self-renewal was a deliberate and $\mathrm{T}$ cell-dependent event for the CD11c+ MHC II- lineage- progenitor cell population.

68

Int Arch Allergy Immunol 2008;147:59-73

\section{Discussion}

This report investigated the effect of i.n. SEA administration on the lung CD11c+ population. We demonstrated for the first time that SEA caused rapid increases in the lung of two different CD11c+ populations. The reason behind this phenomenon was the profound effect of staphylococcal enterotoxins on the lung with the ability to induce migration and self-renewal of these subpopulations. These results underscore the fact that effects of SAgs on the adaptive immune system are preceded by robust activation of the innate immune sys- 
Fig. 6. Lung restricts entry of cells from blood 2 days after i.n. SEA challenge. a Schematic showing GFP transfer experiment. $\mathbf{b}$ Bar graph shows the percentage of bulk GFP+ cells entering the lung or mediastinal LN (MedLN) from blood, 2 days after challenge. Fold difference in SEA over BSS treatment for both lung and mediastinal LN is indicated by the arrows. Data are from 3 independent experiments $(n=7$ for the BSS and $n=7$ for the SEA group) represented as mean \pm SEM. c Gating strategy to detect lineage- CD11c+ MHC IIGFP+ population in the lung and mediastinal LN 2 days after BSS or SEA i.n. challenge. For the lung, lineage- cells (10.5\%; top left panel) were first gated, from which CD11c and MHC II expression was determined. The CD11c+ MHC IIpopulation $(3.64 \%)$ was then gated to track the transferred GFP+ cells. Similar analysis was performed for the mediastinal LN too (bottom panel). Data are from 1 representative experiment of 3 performed.

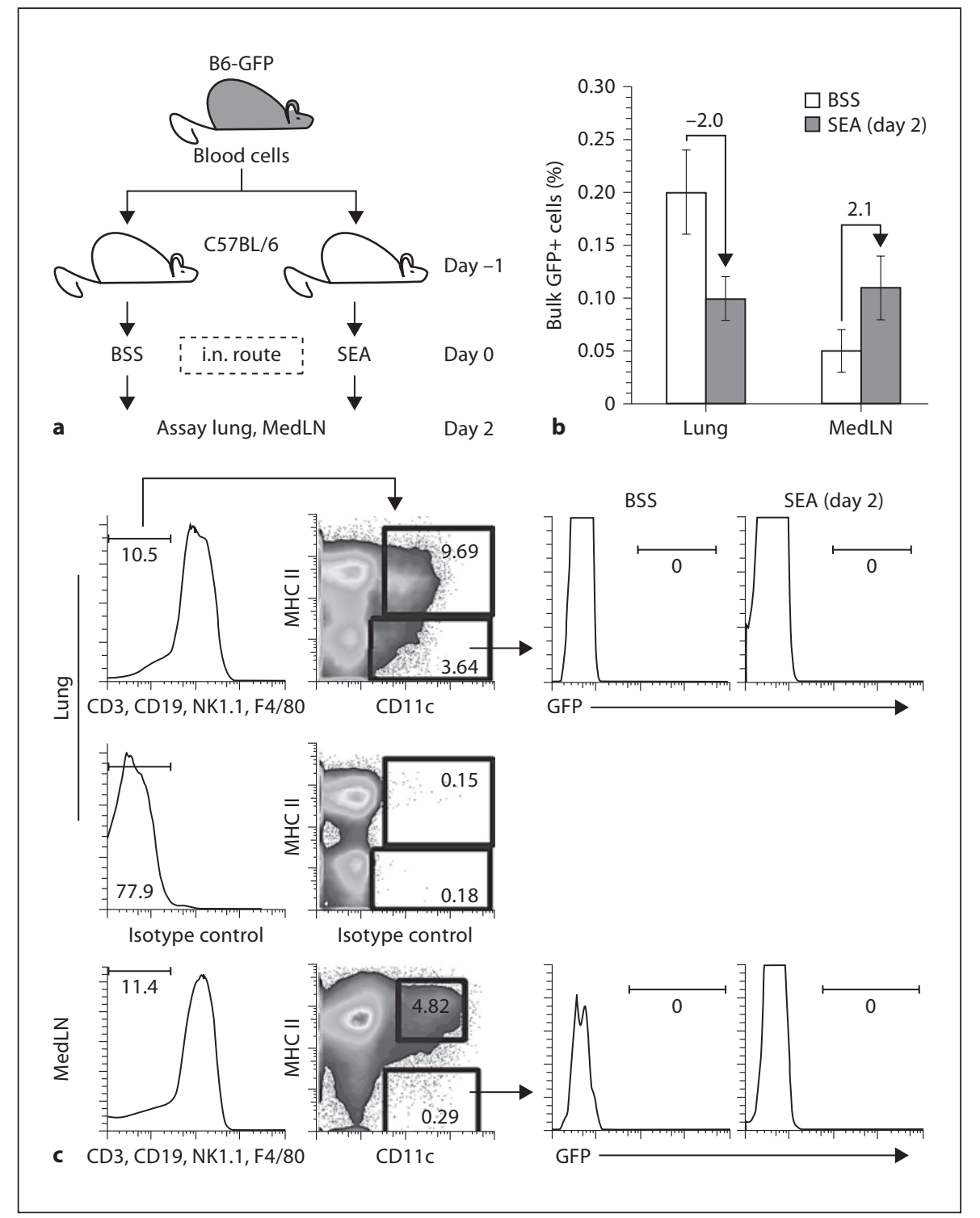

tem, although they themselves are dependent upon $\mathrm{T}$ cells.

DCs migrate from the periphery to the LNs or the site of inflammation [28]. They have a very short half-life, which is further reduced under conditions of stress [3436]. Thus an increase in the total CD11c+ cells in a tissue would most probably be due to cells migrating from the periphery. As mentioned earlier, increases in the CD11c+ population occurred in two waves, with the first wave resulting in increased numbers of CD11c+ MHC II+ DCs on day 1 (fig. 1b). This increase could partly be due to DCs migrating from the blood; alternatively putative immediate DC precursors have been recently described in the lung [30] and these precursors are known to give rise to CD11c+ MHC II+ DCs. Therefore there is the possibility that SAg challenge could induce these precursors to give rise to DCs. Most likely the mechanism behind increased DC numbers on day 1 is a combination of the above-mentioned factors.

Previously, we have shown that i.p. injection of SEA could induce the activation of conventional (all DCs except plasmacytoid DCs) and plasmacytoid DCs in the spleen [22]. Similarly i.n. SEA challenge also induced the upregulation of DC activation markers like CD80, CD86 and CD40 on CD11c ${ }^{\text {hi }} \mathrm{MHC}$ II+ cells in the lung (fig. 1c). Thus SAgs could also cause the activation of DCs in the

Int Arch Allergy Immunol 2008;147:59-73 


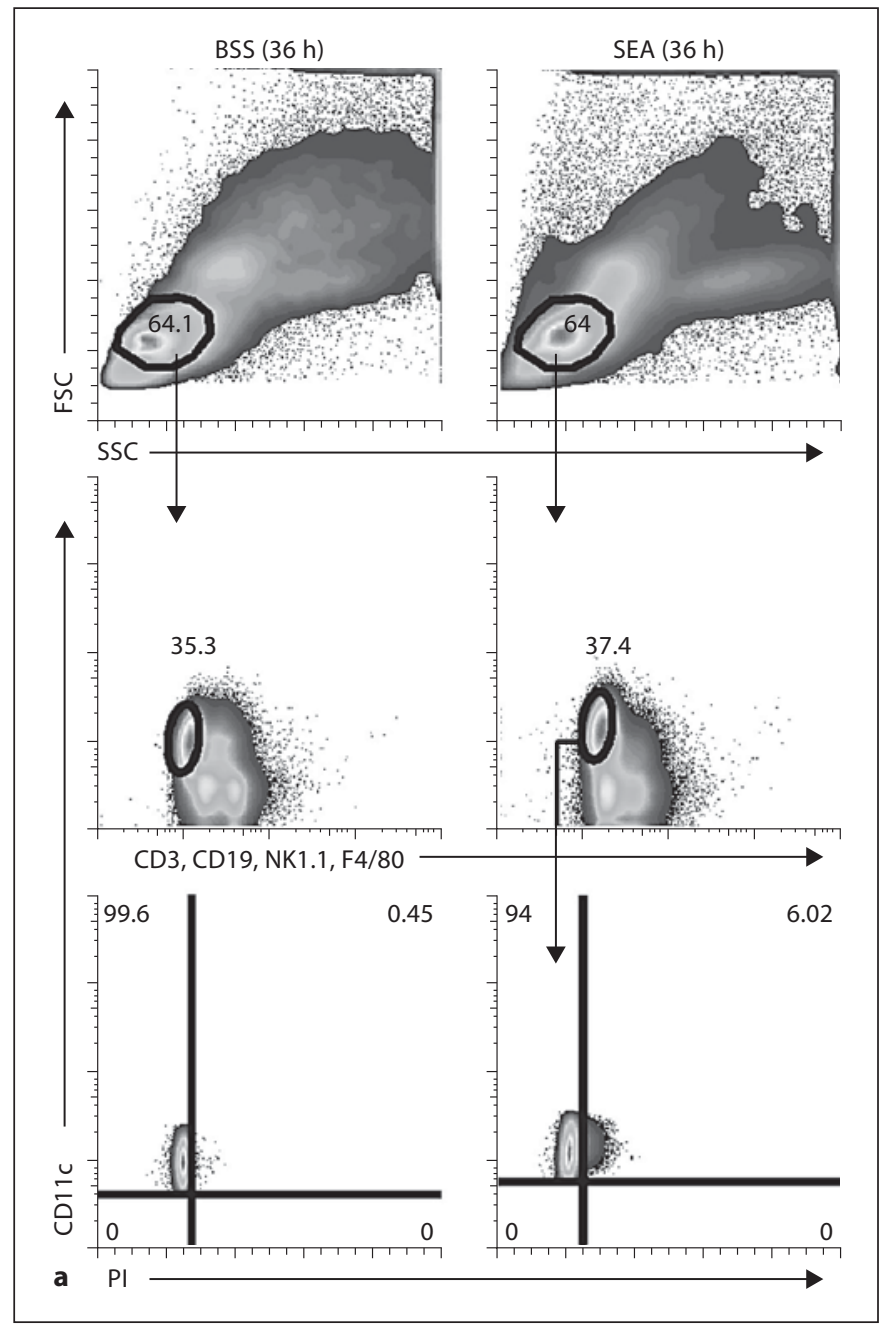

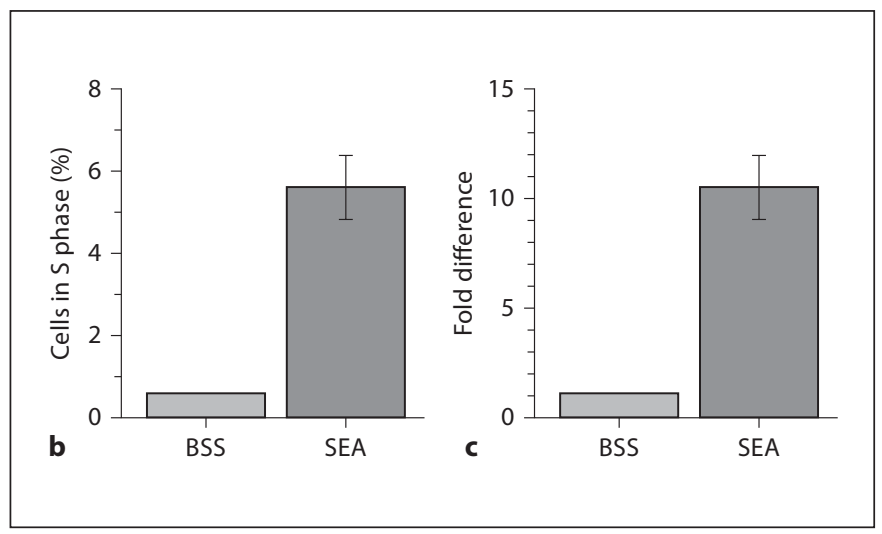

Fig. 7. Lineage- CD11c+ MHC II- cells self-renew in the lung in response to pulmonary SEA challenge. a Gating strategy to detect lung lineage- CD11c+ MHC II- cells entering cell cycle, $36 \mathrm{~h}$ postSEA challenge. Data are from 1 representative experiment of 3 performed. $\mathbf{b}$ The bar graph shows the percentage of CD11c+ MHC II- lineage- cells in S phase of cell cycle. $\mathbf{c}$ The bar graph shows the average fold difference in percentage of SEA-treated CD11c+ MHC II- lineage- cells in S phase of cell cycle over the vehicle-alone BSS treatment. The bar graphs were generated by calculating the fold difference of SEA over BSS treatment in each individual mouse, and then calculating the mean fold difference and its SEM. All data are from 3 independent experiments $(n=7$ for the BSS and $n=7$ for the SEA group) represented as mean \pm SEM.

Table 2. GFP+ lineage- CD11c+ MHC II- cells fail to migrate from blood to lung or mediastinal LN (MedLN) after i.n. SEA challenge

\begin{tabular}{|c|c|c|c|c|c|c|c|c|c|}
\hline \multirow[t]{3}{*}{ Experiment } & \multirow[t]{3}{*}{ Mouse } & \multicolumn{4}{|c|}{ Lung } & \multicolumn{4}{|c|}{ MedLN } \\
\hline & & \multicolumn{2}{|c|}{ \% CD11c+MHCII+ } & \multicolumn{2}{|c|}{ \% CD11c+MHCII- } & \multicolumn{2}{|c|}{ \% CD11c+MHCII+ } & \multicolumn{2}{|c|}{$\%$ CD11c+MHCII- } \\
\hline & & BSS & SEA & BSS & SEA & BSS & SEA & BSS & SEA \\
\hline \multirow[t]{3}{*}{1} & 1 & 0.04 & 0 & 0 & 0 & 0 & 0.05 & 0 & 0 \\
\hline & 2 & 0 & 0.02 & 0 & 0 & 0 & 0.07 & 0 & 0 \\
\hline & 3 & 0.30 & 0 & 0 & 0 & 0 & 0 & 0 & 0 \\
\hline \multirow[t]{2}{*}{2} & 1 & 0.06 & 0.07 & 0 & 0.01 & 0 & 0 & 0 & 0 \\
\hline & 2 & 0.15 & 0 & 0 & 0 & 0.20 & 0.09 & 0 & 0 \\
\hline \multirow[t]{2}{*}{3} & 1 & 0.77 & 0.36 & 0.02 & 0.01 & 0.04 & 0 & 0 & 0 \\
\hline & 2 & 0.07 & 0.27 & 0.01 & 0.005 & 0 & 0.01 & 0 & 0 \\
\hline
\end{tabular}

GFP blood cells $\left(0.8-2 \times 10^{7}\right)$ were adoptively transferred to B6 mice on day -1 . On day 0 , recipient mice were challenged with BSS or $1 \mu \mathrm{g}$ of SEA delivered via the i.n. route. The mice were then sacrificed on day 2 and lung and MedLN were isolated to track GFP+ cells. Data represent percent of lineage- CD11c+ MHC II+ GFP+ cells and percent of lineage- CD11c+ MHC II- GFP+ detected in lung and MedLN and are from 3 different experiments $(n=7)$. 
Table 3. Absence of T cells inhibits self-renewal of CD11c+ MHC II- cell population after SEA challenge

\begin{tabular}{|c|c|c|c|c|c|}
\hline \multirow{3}{*}{$\begin{array}{l}\text { Experi- } \\
\text { ment }\end{array}$} & \multirow[t]{3}{*}{ Mouse } & \multicolumn{4}{|c|}{ Cells in S phase, \% } \\
\hline & & \multicolumn{2}{|c|}{ C57BL/6 } & \multicolumn{2}{|c|}{ TCR $\beta \delta$ KO } \\
\hline & & BSS & SEA & BSS & SEA \\
\hline \multirow[t]{2}{*}{1} & 1 & 1.04 & 5.2 & 0.3 & 0.63 \\
\hline & 2 & & & 0.66 & 0.13 \\
\hline \multirow[t]{2}{*}{2} & 1 & 0.55 & 2.58 & 0.13 & 0.27 \\
\hline & 2 & & & 0.32 & 0.35 \\
\hline \multirow[t]{2}{*}{3} & 1 & 0.68 & 2.58 & 0.35 & 1 \\
\hline & 2 & & & 0.42 & 0.95 \\
\hline
\end{tabular}

C57BL/6 or B6 TCR $\beta \delta \mathrm{KO}$ mice were treated with BSS or $1 \mu \mathrm{g}$ of SEA. $36 \mathrm{~h}$ after challenge, lung CD11c+ MHC II- cells were obtained by depleting MHC II+ cells and then positively selecting for CD11c. Gating strategy, similar to the one performed in figure $7 \mathrm{a}$, was done to detect lineage- CD11c+ MHC II- cells entering cell cycle $36 \mathrm{~h}$ post-SEA challenge. Data represent percent of lineage- CD11c+ MHC II- cells in S phase of cell cycle and are from 3 different experiments $[\mathrm{n}=3(\mathrm{C} 57 \mathrm{BL} / 6)$ or $\mathrm{n}=6(\mathrm{~B} 6 \mathrm{TCR} \beta \delta$ $\mathrm{KO})$ ].

lung apart from inducing accumulation. However the CD11c+ MHC II- population expressed very low levels of these activation markers (fig. $2 \mathrm{~b}$ ) and these data are consistent with existing reports about this population [37]. Major DC subsets that have been characterized in the lung [15] were also identified after SEA challenge, with myeloid DCs (CD11c+ MHC II+ CD11b+) being the predominant DC subset (data not shown). Thus, the CD11c ${ }^{\text {hi }}$ MHC II+ cells, identified in the lung, were DCs which were activated and increased in numbers in response to SEA pulmonary challenge.

CD11c expression is rather promiscuous, with a variety of cell types expressing this marker on their surface $[38,39]$. Therefore studying the CD11c+ MHC II- cell population was difficult, as this population was heterogeneous. One of the major concerns while examining CD11c+ lung cells was the fact that one could be studying alveolar macrophages [16] instead of a putative progenitor population. In our studies, we exclude the possibility that these cells could be macrophages by gating out $\mathrm{Si}$ glec-F+ and F4/80+ cells from the analysis. Siglec-F-expressing macrophages found in abundance in the lung [16] are double positive for Siglec-F and CD11c, and hence contribute to a large percentage of the total CD11c+ pulmonary cells [17]. This population was identified in the forward and side scatter gates and carefully excluded from the analysis (online suppl. fig. 1, www.karger.com/ doi/10.1159/000128660). Additionally while examining CD11c+ MHC II- cells, T, B, NK cells and macrophages also had to be excluded and this was done based on CD3, CD19, NK1.1 and F4/80 expression. Markers like CD4, CD8, B220, CD11b and Gr-1 were not used for exclusion studies as these have been reported to be present on CD11c+ MHC II- population [29, 37]. Ultimately there was indeed an increase in the percentage of CD11c+ MHC II- cell population after excluding all possible contaminants (fig. 3b). This population has been described as a putative DC precursor population found mainly in blood but has also been reported to be present in the lung [29, $30,32]$.

A peripheral blood cell tracking technique was employed to determine if migration from blood was the reason behind increased numbers of DCs in the tissues (fig. 4a). Apart from CD11c+ MHC II- population, blood also contains CD11c+ MHC II+ DCs, albeit in very low numbers $[40,41]$. The percentage of DCs and CD11c+ MHC II- population in B6-GFP blood was comparable to naive $\mathrm{B} 6$ blood (data not shown). GFP+ DCs could be detected in the MLN, PLN and spleen after i.p. SEA challenge (fig. 4d). Blood DCs have been reported to be inefficient in migrating across the high endothelial venules although reports suggest that the immediate precursors found in blood have this capacity $[29,42]$. Thus GFP+ DCs observed in the LNs could be GFP+ CD11c+ MHC II- precursors migrating from the blood and upregulating MHC II expression to become DCs in the LNs.

We used this GFP transfer system to investigate if the increased DC numbers on day 1 was the result of migration from blood. After GFP transfer and i.n. SEA challenge, GFP+ DCs were observed in the lung (fig. 5c). Although DCs from blood have been reported to be inefficient in crossing high endothelial venules to enter LNs, they are efficient in trafficking to tissues [42, 43]. However, the fold increase of GFP+ DCs resulting from migration did not completely account for the increase in DC numbers seen on day 1 . This could be due to the fact that the transferred cells would also migrate to tissues like spleen, probably with much greater affinity, thereby diluting the number of cells available to migrate to the lung.

The most surprising result was observed on day 2, when lung restricted the entry of cells from the blood by 2 -fold (fig. 6b), while at the same time the mediastinal LN had doubled its intake. The reason for this restriction could be due to the fact that lung, in itself, was a reservoir for progenitors which could give rise to a number of im- 
mune cell types. Alternatively, there is also the possibility of emigration of cells from the lung to the draining mediastinal LN. The lung may be programmed in such a way that at the height of inflammation, it possesses a sufficient pool of progenitors that could generate cells capable of mounting an immune response. Supporting this theory, very few GFP+ CD11c+ MHC II- cells could be tracked in the lung (fig. 6c). However when CD11c+ MHC II- cells were isolated from lung and analyzed for DNA content a small percentage of these cells were in the $S$ phase of cell cycle $36 \mathrm{~h}$ post-SEA challenge (fig. $7 \mathrm{a}$ ). This suggests that replenishment of the putative progenitor cell population could be an in situ self-renewal phenomenon. Thus we hypothesize that lung probably has the capacity to regenerate cell types after a powerful pulmonary immune stimulus from an existing pool of progenitors without having to depend solely on migration from bone marrow.

\section{Acknowledgments}

This work was supported by NIH grants, AI 142858 and AI 52108 (ATV).

\section{References}

1 Proft T, Fraser JD: Bacterial superantigens. Clin Exp Immunol 2003;133:299-306.

-2 Scherer MT, Ignatowicz L, Winslow GM, Kappler JW, Marrack P: Superantigens: bacterial and viral proteins that manipulate the immune system. Annu Rev Cell Biol 1993;9: 101-128.

$>3$ Fraser J, Arcus V, Kong P, Baker E, Proft T: Superantigens - powerful modifiers of the immune system. Mol Med Today 2000;6: 125-132.

4 Herman A, Kappler JW, Marrack P, Pullen AM: Superantigens: mechanism of T-cell stimulation and role in immune responses. Annu Rev Immunol 1991;9:745-772.

$\checkmark 5$ Kotzin BL, Leung DY, Kappler J, Marrack P: Superantigens and their potential role in human disease. Adv Immunol 1993;54:99166.

$\checkmark 6$ Bachert C, Gevaert P, van Cauwenberge P: Staphylococcus aureus enterotoxins: a key in airway disease? Allergy 2002;57:480-487.

$\checkmark 7$ Choudhurry RS, Melles DC, Eadie K, Vos M, Wertheim HF, Verbrugh HA, van Belkum A, van Leeuwen WB: Direct detection of human Staphylococcus aureus carriage in the nose using the Lightcycler Staphylococcus kit. J Microbiol Methods 2006;65:354-356.

$\checkmark 8$ Wertheim HF, Melles DC, Vos MC, van Leeuwen W, van Belkum A, Verbrugh HA, Nouwen JL: The role of nasal carriage in Staphylococcus aureus infections. Lancet Infect Dis 2005;5:751-762.

-9 Van Zele T, Gevaert P, Watelet JB, Claeys G, Holtappels G, Claeys C, van Cauwenberge P, Bachert C: Staphylococcus aureus colonization and $\operatorname{IgE}$ antibody formation to enterotoxins is increased in nasal polyposis. J Allergy Clin Immunol 2004;114:981-983.

-10 Rohde G, Gevaert P, Holtappels G, Borg I, Wiethege A, Arinir U, Schultze-Werninghaus $\mathrm{G}$, Bachert $\mathrm{C}$ : Increased IgE-antibodies to Staphylococcus aureus enterotoxins in patients with COPD. Respir Med 2004;98:858864. Renz H, Herz U: The bidirectional capacity
of bacterial antigens to modulate allergy and
asthma. Eur Respir J 2002;19:158-171.

12 Rajagopalan G, Sen MM, Singh M, Murali NS, Nath KA, Iijima K, Kita H, Leontovich AA, Gopinathan U, Patel R, David CS: Intranasal exposure to staphylococcal enterotoxin B elicits an acute systemic inflammatory response. Shock 2006;25:647-656.

13 Rajagopalan G, Iijima K, Singh M, Kita H, Patel R, David CS: Intranasal exposure to bacterial superantigens induces airway inflammation in HLA class II transgenic mice. Infect Immun 2006;74:1284-1296.

14 Herz U, RuckertR, Wollenhaupt K, Tschernig T, Neuhaus-Steinmetz U, Pabst R, Renz H: Airway exposure to bacterial superantigen (SEB) induces lymphocyte-dependent airway inflammation associated with increased airway responsiveness - a model for non-allergic asthma. Eur J Immunol 1999;29:10211031.

15 de Heer HJ, Hammad H, Kool M, Lambrecht BN: Dendritic cell subsets and immune regulation in the lung. Semin Immunol 2005;17: 295-303.

16 von Garnier C, Filgueira L, Wikstrom M, Smith M, Thomas JA, Strickland DH, Holt PG, Stumbles PA: Anatomical location determines the distribution and function of dendritic cells and other APCs in the respiratory tract. J Immunol 2005; 175:16091618.

17 Sung SS, Fu SM, Rose CE Jr, Gaskin F, Ju ST, Beaty SR: A major lung CD103 (alphaE)beta7 integrin-positive epithelial dendritic cell population expressing Langerin and tight junction proteins. J Immunol 2006;176: 2161-2172.

18 de Heer HJ, Hammad H, Soullie T, Hijdra D, Vos N, Willart MA, Hoogsteden HC, Lambrecht $\mathrm{BN}$ : Essential role of lung plasmacytoid dendritic cells in preventing asthmatic reactions to harmless inhaled antigen. J Exp Med 2004;200:89-98.
19 van Rijt LS, Lambrecht BN: Dendritic cells in asthma: a function beyond sensitization. Clin Exp Allergy 2005;35:1125-1134.

20 van Rijt LS, Jung S, Kleinjan A, Vos N, Willart M, Duez C, Hoogsteden HC, Lambrecht $\mathrm{BN}$ : In vivo depletion of lung CD11c+ dendritic cells during allergen challenge abrogates the characteristic features of asthma. J Exp Med 2005;201:981-991.

21 Muraille E, De Trez C, Pajak B, Brait M, Urbain J, Leo O: T cell-dependent maturation of dendritic cells in response to bacterial superantigens. J Immunol 2002;168:43524360.

22 Muralimohan G, Vella AT: A role for IFNgamma in differential superantigen stimulation of conventional versus plasmacytoid DCs. Cell Immunol 2006;242:9-22.

23 Rossi RJ, Muralimohan G, Maxwell JR, Vella AT: Staphylococcal enterotoxins condition cells of the innate immune system for Tolllike receptor 4 stimulation. Int Immunol 2004;16:1751-1760.

24 Mehindate K, Thibodeau J, Dohlsten M, Kalland T, Sekaly RP, Mourad W: Cross-linking of major histocompatibility complex class II molecules by staphylococcal enterotoxin A superantigen is a requirement for inflammatory cytokine gene expression. J Exp Med 1995;182:1573-1577.

-25 Hudson KR, Tiedemann RE, Urban RG, Lowe SC, Strominger JL, Fraser JD: Staphylococcal enterotoxin A has two cooperative binding sites on major histocompatibility complex class II. J Exp Med 1995;182:711720.

26 Okabe M, Ikawa M, Kominami K, Nakanishi T, Nishimune Y: 'Green mice' as a source of ubiquitous green cells. FEBS Lett 1997;407: 313-319.

27 Unkeless JC: Characterization of a monoclonal antibody directed against mouse macrophage and lymphocyte Fc receptors. J Exp Med 1979;150:580-596. 
28 Banchereau J, Steinman RM: Dendritic cells and the control of immunity. Nature 1998; 392:245-252.

-29 Yoneyama H, Matsuno K, Zhang Y, Nishiwaki T, Kitabatake M, Ueha S, Narumi S, Morikawa S, Ezaki T, Lu B, Gerard C, et al: Evidence for recruitment of plasmacytoid dendritic cell precursors to inflamed lymph nodes through high endothelial venules. Int Immunol 2004;16:915-928.

-30 Wang H, Peters N, Laza-Stanca V, Nawroly N, Johnston SL, Schwarze J: Local CD11c+ MHC class II- precursors generate lung dendritic cells during respiratory viral infection, but are depleted in the process. J Immunol 2006;177:2536-2542.

- 31 Diao J, Winter E, Cantin C, Chen W, Xu L, Kelvin D, Phillips J, Cattral MS: In situ replication of immediate dendritic cell (DC) precursors contributes to conventional DC homeostasis in lymphoid tissue. J Immunol 2006;176:7196-7206.

-32 del Hoyo GM, Martin P, Vargas HH, Ruiz S, Arias CF, Ardavin C: Characterization of a common precursor population for dendritic cells. Nature 2002;415:1043-1047.

-33 Lee SJ, Myers L, Muralimohan G, Dai J, Qiao Y, Li Z, Mittler RS, Vella AT: 4-1BB and OX40 dual costimulation synergistically stimulate primary specific CD8 T cells for robust effector function. J Immunol 2004;173:30023012
34 De Smedt T, Pajak B, Muraille E, Lespagnard L, Heinen E, De Baetselier P, Urbain J, Leo O, Moser M: Regulation of dendritic cell numbers and maturation by lipopolysaccharide in vivo. J Exp Med 1996;184:1413-1424.

35 Kamath AT, Pooley J, O’Keeffe MA, Vremec D, Zhan Y, Lew AM, D'Amico A, Wu L, Tough DF, Shortman K: The development, maturation, and turnover rate of mouse spleen dendritic cell populations. J Immunol 2000;165:6762-6770.

36 Kamath AT, Henri S, Battye F, Tough DF, Shortman K: Developmental kinetics and lifespan of dendritic cells in mouse lymphoid organs. Blood 2002;100:1734-1741.

37 Diao J, Winter E, Chen W, Cantin C, Cattral MS: Characterization of distinct conventional and plasmacytoid dendritic cell-committed precursors in murine bone marrow. J Immunol 2004;173:1826-1833.

38 Huleatt JW, Lefrancois L: Antigen-driven induction of CD11c on intestinal intraepithelial lymphocytes and CD8+ T cells in vivo. J Immunol 1995; 154:5684-5693.

39 Chan CW, Crafton E, Fan HN, Flook J, Yoshimura K, Skarica M, Brockstedt D, Dubensky TW, Stins MF, Lanier LL, Pardoll DM, et al: Interferon-producing killer dendritic cells provide a link between innate and adaptive immunity. Nat Med 2006;12:207-213.
40 O'Keeffe M, Hochrein H, Vremec D, Scott B, Hertzog P, Tatarczuch L, Shortman K: Dendritic cell precursor populations of mouse blood: identification of the murine homologues of human blood plasmacytoid preDC2 and CD11c+ DC1 precursors. Blood 2003;101:1453-1459.

41 Donnenberg VS, O’Connell PJ, Logar AJ, Zeevi A, Thomson AW, Donnenberg AD: Rare-event analysis of circulating human dendritic cell subsets and their presumptive mouse counterparts. Transplantation 2001; 72:1946-1951.

42 Cavanagh LL, Bonasio R, Mazo IB, Halin C, Cheng G, van der Velden AW, Cariappa A, Chase C, Russell P, Starnbach MN, Koni PA, et al: Activation of bone marrow-resident memory T cells by circulating, antigen-bearing dendritic cells. Nat Immunol 2005;6: 1029-1037.

43 Lappin MB, Weiss JM, Delattre V, Mai B, Dittmar H, Maier C, Manke K, Grabbe S, Martin S, Simon JC: Analysis of mouse dendritic cell migration in vivo upon subcutaneous and intravenous injection. Immunology 1999;98:181-188. 